\title{
Numerical Simulation and Experimental Test on the Burst Pressure of ASME A106 Steel Pipe
}

\author{
Ali Akram ${ }^{1, *}$, Zahiraniza Mustaffa ${ }^{1}$, and Thar Albarody ${ }^{2}$ \\ ${ }^{1}$ Universiti Teknologi PETRONAS, Civil and Environmental Engineering Department, 32610, Seri \\ Iskandar, Perak, Malaysia \\ ${ }^{2}$ Universiti Teknologi PETRONAS, Mechanical Engineering Department, 32610, Seri Iskandar, \\ Perak, Malaysia
}

\begin{abstract}
A thermosetting infield liner (IFL) was developed using glass epoxy in response of the need for an optimized cost repair method. A burst test was conducted using ASME 106 steel pipes to measure their burst pressure which will later be used to measure the performance of the thermosetting IFL. Three specimens were prepared for the burst test using a custom made burst rig. The burst pressure obtained was on average 245 bar of pressure. A numerical simulation was also conducted using ANSYS to create a validated model for future use in developing the thermosetting IFL. The results of the simulation show a $7 \%$ difference with the experiment results.
\end{abstract}

Keywords: Pipeline, Offshore, Rehabilitation, Corrosion, Composite material

\section{Introduction}

The integrity of pipelines has always been the highest priority for pipeline operators especially for aging pipelines. Pipelines are susceptible to failure due to several source of damages where external interference and corrosion [1]-[3] are the highest contributors as shown in Figure 1 provided by DNV-RP-F116.

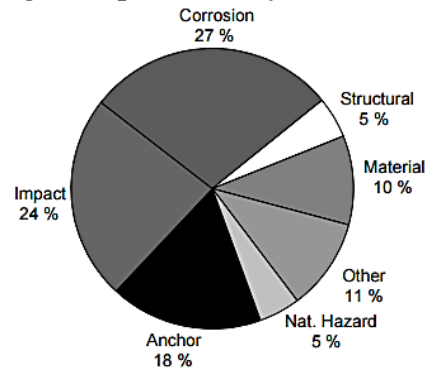

a) The North Sea

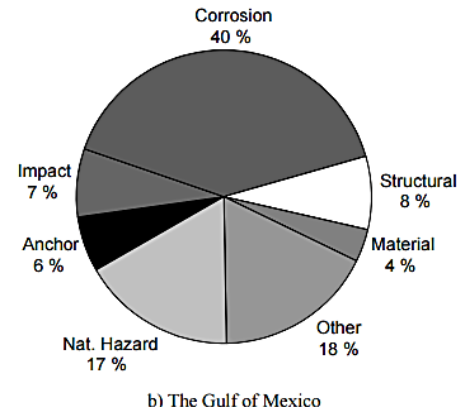

b) The Gulf of Mexico

Fig. 1. Pipeline failures in the North Sea and the Gulf of Mexico.

\footnotetext{
*Corresponding author: aliakram92@gmail.com
} 
Rehabilitation are conducted in order to extend the service life of aging pipelines which depends on the length or severity of the damage. The issue arises when a long length of the pipeline experiences damage such as wall thinning due to corrosion internally and externally. In such cases, pipeline replacement is inevitable. Pipeline replacement is a time consuming and costly operation as it requires extensive preparation involving specialized personnel and dedicated service vessel [2]. The typical cost involving pipeline replacement is around 100 million USD, as in the case with a 24 inch pipe in Nigeria in 2009 [4].

Therefore, a new repair method was recently developed by Petronas Carigali (PCSB) aiming to optimize repair costs. The repair method was initiated in response to an aging pipeline installed in the Samarang field Sabah Operation. It was determined that the line is required to operate for another twenty five years but is experiencing some wall loss at few locations, making it costly to perform maintenance and repair.

\section{Infield Liner}

The infield liner (IFL) is a repair method developed in a joint effort by Petronas and Anticorrosion Protective Systems (APS). The basic idea behind the IFL is to implement a corrosion resistant barrier in form of a liner inside the pipeline which will not only eliminate corrosion activities but also provide additional strength to the deteriorating host pipe [5].

Fig. 2. Infield Liner.

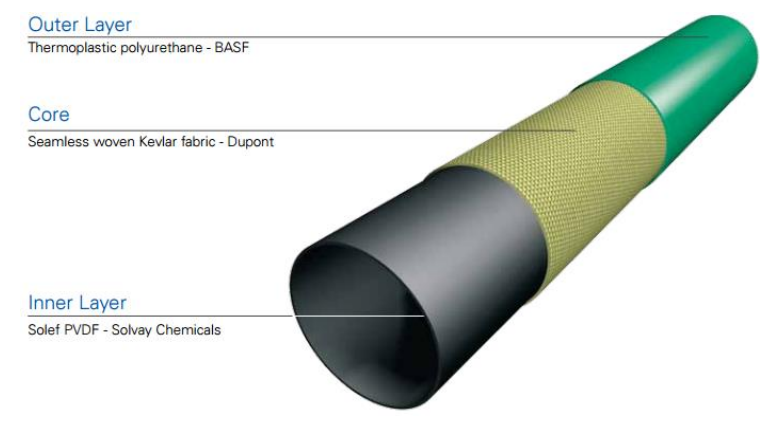

Generally, the IFL consists of reinforcement fibers made of aramid covered in thermoplastic layers. The inner thermoplastic layer is made of Solev PVDF while the outer layer is made of polyurethane for abrasion resistance. The IFL is designed to be able to withstand 120 bar of pressure and perform in sour hydrocarbon service conditions of up to $110^{\circ} \mathrm{C}[5]$.

The concept of the IFL however is not an unusual method as it has already been practiced to repair onshore pipelines. One example is the Primus line by Rädlinger, a reinforced thermoplastic pipe made from polyethylene and Kevlar developed for various onshore applications as shown in Figure 3. In addition to that, due to concerns on the permeability of current liners [6]-[10], some liners are engineered for corrosive application as shown in Figure 4. 


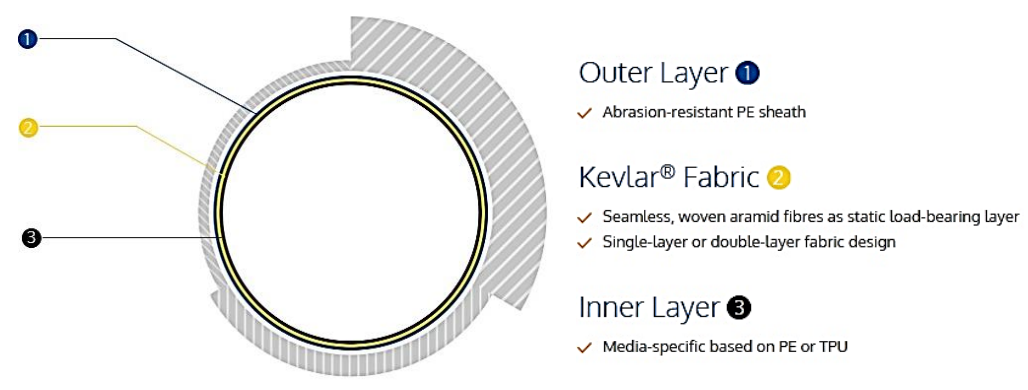

Fig. 3. Design of the Primus Line [5].

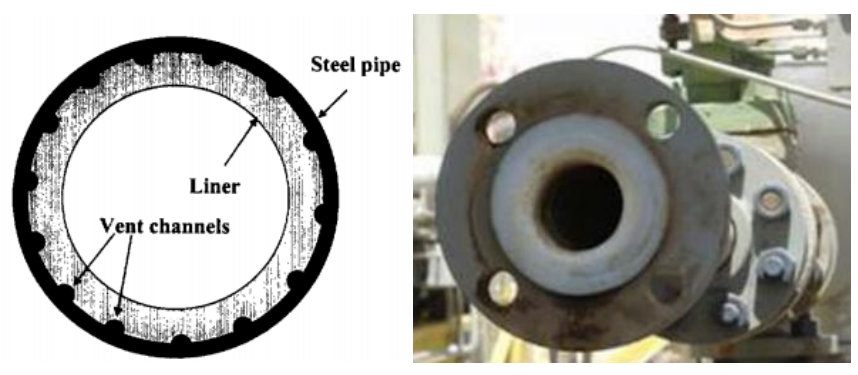

Fig. 4. Engineered Liners [11], [12].

However, it is believed that replacing the thermoplastic resin with thermosets will allow further improvement in its performance. Thus this research is dedicated to investigate the performance of IFL using thermosetting material, namely epoxy with glass fiber in form of prepreg.

\subsection{Composite material}

Thermosettings and thermoplastics are the two main polymers used for structural applications. The difference between these polymers are in the type of bonds. Thermosets are formed through permanent cross linking between the molecules while thermoplastics are formed through weak Van der Waals forces [13]. As a result, thermosets have higher strength compared with thermoplastics. However, thermosets are unable to melt or revert into their viscous form due to their three-dimensional structure, thus are unrecyclable.

Composite material is seen as an attractive alternative in the offshore industry due to its high strength to weight ratio. The properties are largely dependent on its components namely the matrix and the reinforcement where the matrix discussed will be a thermosetting resin owing to its higher mechanical properties. In offshore applications, [14] simplifies the selection criteria for resins into three which are cost, flammability and mechanical properties. However, chemical resistance should also be considered due to the presence of corrosive substances. The matrix is selected from the most common thermoset used for structural purposes that is polyester, vinyl ester, and epoxy. These materials are known for their good mechanical strength and chemical resistance. Among these resins, epoxy is the popular choice as it is regarded for its superior mechanical property and low degradation from water absorption [15].

In terms of reinforcement, carbon fiber and glass fiber are usually chosen due to their strength. There are also cases where aramid fiber is used. Table 1 shows the generalization of their mechanical property as well as cost and toxicity in fire [14], while Table 2 shows a comparison of fiber strength provided by [16]. However, it is difficult to provide an 
accurate figure as it varies with different manufacturers, although it could still serve as a good reference. Thus, Table 3 provides a qualitative approach for comparison between polymers reinforced with the mentioned fibers [17].

Table 1. Mechanical Properties of Thermosetting Resin.

\begin{tabular}{|c|c|c|c|}
\hline Resin & $\begin{array}{c}\text { Mechanical } \\
\text { integrity }\end{array}$ & $\begin{array}{c}\text { Toxicity in } \\
\text { fire }\end{array}$ & Cost \\
\hline Polyester & $* * * * *$ & $*$ & $* * *$ \\
\hline Vinyl ester & $* * * * * * *$ & $*$ & $* * * * * *$ \\
\hline Epoxy & $* * * * * * * * *$ & $*$ & $* * * * * * * * *$ \\
\hline Phenolic & $* * * * *$ & $* * * *$ & $* * * *$ \\
\hline Mod Acrylic & $* * * *$ & $* * * * * *$ & $* * * *$ \\
\hline
\end{tabular}

Table 2. Mechanical Properties of Reinforcement Fiber.

\begin{tabular}{|c|c|c|c|}
\hline Fiber & E glass & Aramid & Carbon \\
\hline Specific Gravity & 2.54 & 1.44 & 1.56 \\
\hline $\begin{array}{c}\text { Ultimate Tensile } \\
\text { strength (MPa) }\end{array}$ & 1550 & 1379 & 1600 \\
\hline $\begin{array}{c}\text { Young's } \\
\text { Modulus (GPa) }\end{array}$ & 72.4 & 62.05 & 125 \\
\hline
\end{tabular}

Table 3. Qualitative comparison between reinforced polymers.

\begin{tabular}{|c|c|c|c|}
\hline Criterion & Carbon & Aramid & E-Glass \\
\hline Tensile strength & Very good & Very good & Very good \\
\hline Compressive strength & Very good & Inadequate & Good \\
\hline Modulus of elasticity & Very good & Good & Adequate \\
\hline Long term behavior & Very good & Good & Adequate \\
\hline Fatigue behavior & Excellent & Good & Adequate \\
\hline Bulk density & Good & Excellent & Adequate \\
\hline Alkaline resistance & Very good & Good & Inadequate \\
\hline Price & Adequate & Adequate & Very good \\
\hline
\end{tabular}


Based on the material properties shown, the matrix and reinforcement fiber chosen are epoxy and glass fiber respectively for the development of the thermosetting IFL. Although carbon fiber is superior, it is believed that glass fiber also possesses comparable strength.

\subsection{Composite material}

The thermosetting IFL follows the same principle as the original IFL. The only difference is in the material used, as well as the layout of the pipe. The original IFL consists of reinforcement fibers enveloped in thermoplastic layers. On the other hand, the thermosetting IFL will employ reinforcement fibers impregnated with thermosetting resins, which is also known as prepregs. The use of prepregs allows easier fabrication of the thermosetting IFL. Since the prepregs are already impregnated with the desired resin, there is no need to manually apply the resin, thus reducing the errors and defects of fabrication. Nevertheless, it is imperative to determine the performance of the thermosetting IFL through experiment tests. In this paper, the parameter of interest is the burst pressure of the thermosetting IFL which can be measured through a series of burst tests. The first step however is to determine the strength of an intact steel pipe through the burst test before proceeding to the thermosetting IFL.

\section{Methodology}

\subsection{Experiment setup}

The setup for the burst test is shown in Figure 5. The main components of the burst test are the hydraulic pump, pressure gauge, pressure transducer, datalogger, burst rig, and hydraulic hoses to connect all the components. Water is pumped manually using the hydraulic pump to induce internal pressure. The pressure gauge displays the actual pressure inside the specimen while the pressure transducer relays the reading to the datalogger for data recording.

The burst rig is designed based on other works such as by [18] and [19]. Despite many designs, the basic setup of a burst test remains the same, that is, a fluid is injected at a constant rate inside a closed vessel to induce internal pressure. The burst rig comprises several parts which needs to be assembled to create the complete rig as shown in Figure 5. The first step is screwing the threaded end caps onto the specimen, which are then clamped together with steel plates connected with twelve steel rods to eliminate tension during the test. The rig is then placed in a steel frame to avoid movement during testing. The dimensions of the burst rig are based on the desired capacity which is up to 500 bar of pressure. The actual assembled burst rig is shown in Figure 6 . 


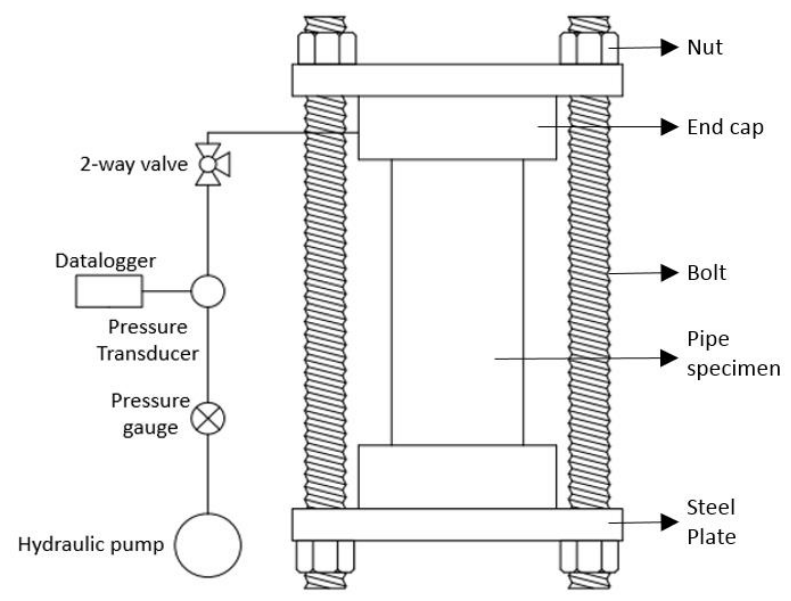

Fig. 5. Burst test setup.

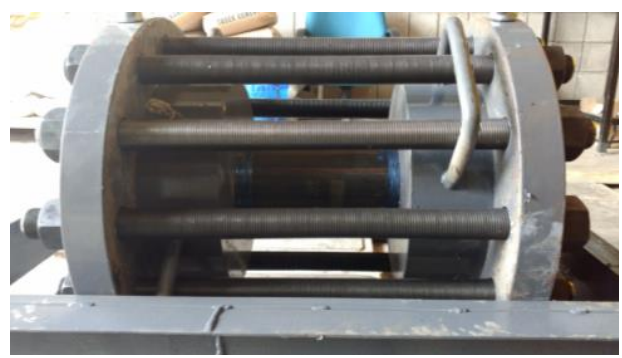

Fig. 6. Assembled burst rig.

\subsection{Specimen design}

The specimen used for the burst test is machined from an ASME 106 steel pipe with an ultimate tensile strength of $492 \mathrm{MPa}$, yield strength of $382 \mathrm{MPa}$, and Young's Modulus of $210 \mathrm{GPa}$. Three pipe specimens are used for the burst test where the dimensions of the pipe specimen is shown in Figure 7. The thickness of the pipe is measured through an ultrasonic test where the average thickness is $3 \mathrm{~mm}$ based on measurements in different locations. The specimen is threaded $50 \mathrm{~mm}$ on each end for attaching to the burst rig. 

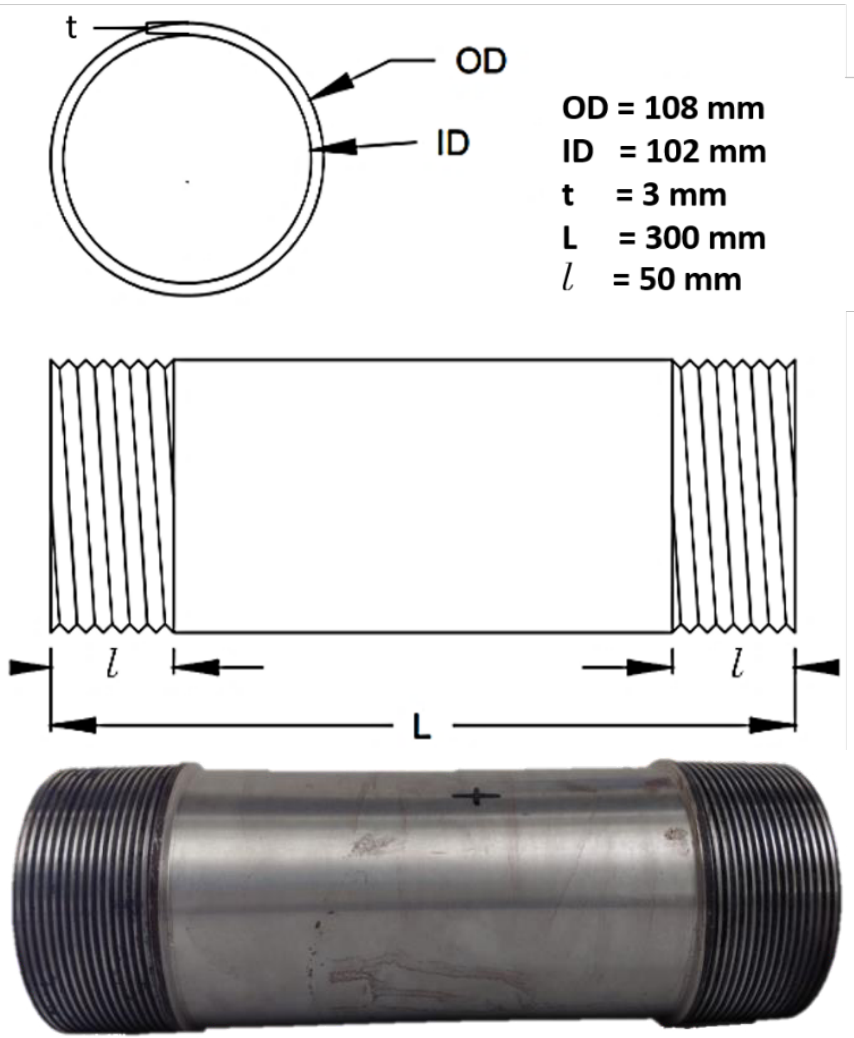

Fig. 7. Specimen design and dimension.

\subsection{Numerical simulation}

The numerical simulation was conducted using ANSYS and the model created in Solid works. In order to conserve the computation time, only a quarter of the pipe was modelled taking advantage of the symmetrical property as shown in Figure 8. The cross section area was restricted in the $\mathrm{x}$-axis while the end area was restricted in the z-axis. A fixed point was applied at the edge of the model as shown in Figure 9. The boundary conditions described resembles a clamped condition similar to the experiment conditions.

The model was meshed with hexahedral elements where 38 elements are in the circumferential direction and 50 elements are in the longitudinal direction. Four elements were used for the wall thickness which is sufficient to simulate the deformation of the pipe accurately [20], [21]. Pressure is applied in the inner surface of the pipe to induce internal pressure. The failure criterion is stress-based where failure is assumed when the von-mises stress reaches the ultimate tensile strength of the material. The simulation conducted is a non-linear analysis where the stress-strain properties used for the material is based on the Ramberg-Osgood equation adopted from [19].

$$
\varepsilon=\frac{\sigma}{E}+\alpha\left(\frac{\sigma}{\sigma_{Y S}}\right)^{n-1}\left(\frac{\sigma}{E}\right)
$$


Where:

$\alpha=1.75$

$n=9.35$

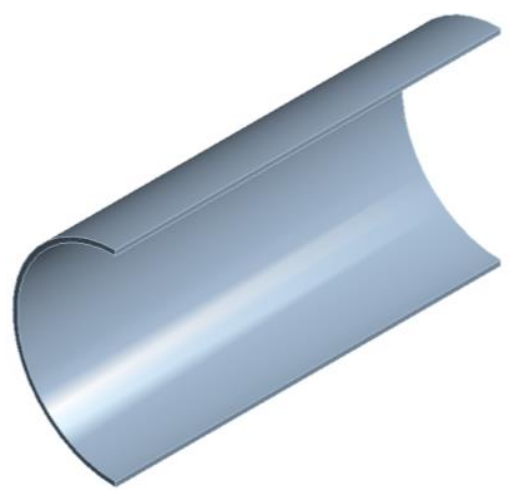

Fig. 8. Quarter model of pipe specimen.

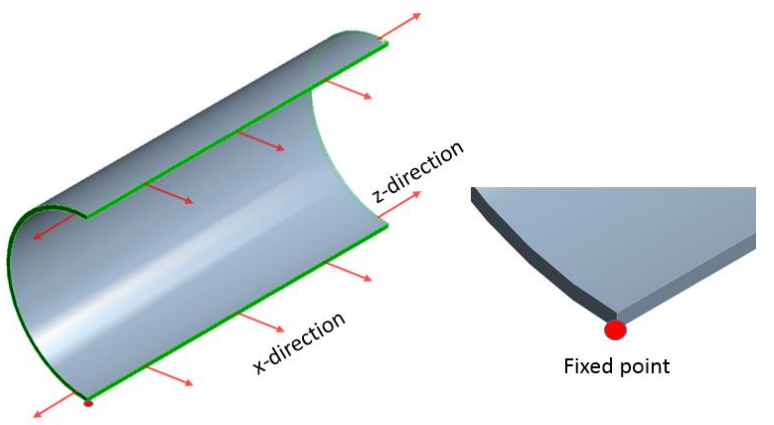

Fig. 9. Boundary conditions.
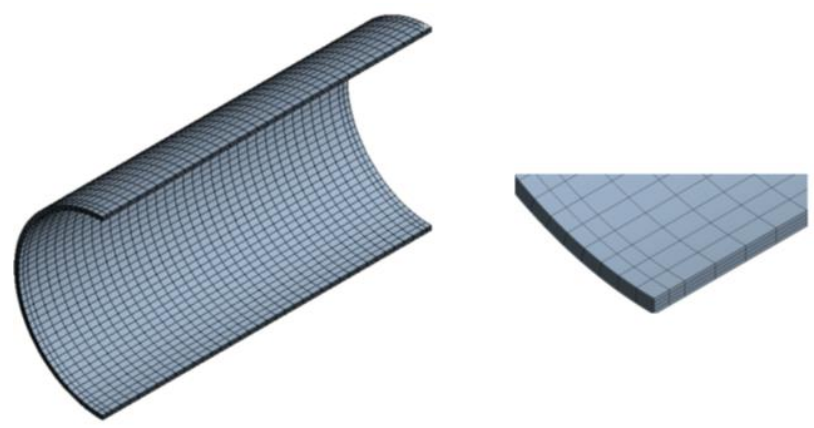

Fig. 10. Meshed model.

\section{Results and discussions}

The results obtained from the burst experiment are the maximum burst pressure for the pipe specimens where the results are shown in Table 4. The different results between the pipe specimens are attributed to the out of roundness of the pipe because seamless pipes have a tolerance allowance of $12.5 \%$ to $15 \%$ out of roundness. This causes a variation of thickness of the pipe where failure will occur on the thinnest part of the pipe. Failure occurs in the longitudinal direction as shown in Figure 11. 
The numerical results are compared with the experiment results and also with an empirical equation, the Barlow equation shown below, for validation purposes. The results are tabulated in Table 5 .

$$
P_{\mathrm{i}}=\frac{2 \sigma_{u} t}{D}
$$

Where:

$P_{\mathrm{i}}=$ Internal pressure

$\sigma_{u}=$ Ultimate tensile strength

$t=$ wall thickness

$D=$ Outer diameter

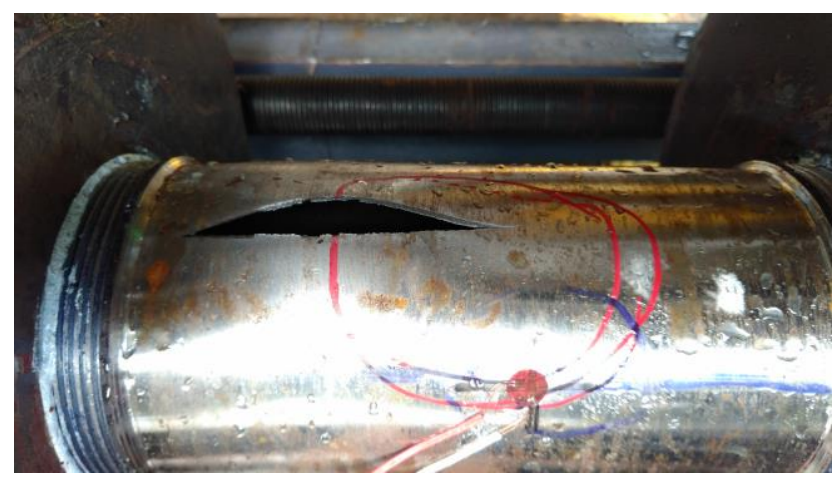

Fig. 11. Pipe failure.

Table 4. Experiment burst pressure.

\begin{tabular}{|c|c|c|c|c|}
\hline Pipe Specimen & $\mathbf{1}$ & $\mathbf{2}$ & $\mathbf{3}$ & Average \\
\hline $\begin{array}{c}\text { Burst pressure, } \\
\boldsymbol{P}_{b} \text { (bar) }\end{array}$ & 250 & 251 & 235 & 245.3 \\
\hline
\end{tabular}

Table 5. Comparison of results.

\begin{tabular}{|c|c|c|c|}
\hline Result & $\begin{array}{c}\text { Experiment, } \\
P_{b} \\
\end{array}$ & $\begin{array}{c}\text { Simulation, } \\
P_{\mathrm{s}} \\
\end{array}$ & $\begin{array}{c}\text { Empirical, } \\
P_{\text {in }} \\
\end{array}$ \\
\hline Pressure (bar) & 245.3 & 262.3 & 289.4 \\
\hline Difference $\left(\frac{x_{n}}{m_{i}}\right)$ & 1 & 1.07 & 1.18 \\
\hline
\end{tabular}

The result from the simulation shows to be comparatively close to the experiment results and the empirical equation and can thus be concluded as validated. The model can therefore be used for further analysis for corroded pipe repaired with thermosetting liner.

\section{Conclusion}

The conclusion of this experiment shows that the strength of the intact pipe specimen is on average at 245 bar. The result was used to validate the simulation result showing a $7 \%$ difference in burst pressure. Another comparison was made using the Barlow formula and the simulation result was proven to yield more accurate results. 


\section{References}

1. N. S. Sulaiman and H. Tan, "Third Party Damages of Offshore Pipeline 海底管道的第三方损伤,” J. Energy Challenges Mech., 1, 1, pp. 1-6, (2014).

2. D. Popineau, P. Wiet, and S. Boulet d'AURIA, "Subsea Pipeline Repair By Composite System." Society of Petroleum Engineers, (2012).

3. A. C. Palmer and R. A. King, Subsea Pipeline Engineering. PennWell, (2004).

4. K. Mohammadi, "Repair methods for damaged pipeline beyond diving depth," University of Stavanger, (2011).

5. R. A. Walters, "IFLTM - A Novel Approach to the Rehabilitation of Sub-Sea Hydrocarbon Pipelines Using High Performance Solef PVDF Flexible Kevlar Reinforced Liners." Society of Petroleum Engineers, (2015).

6. A. Simonsen, E. Janssen, and C. Paton, "Inspection and monitoring techniques for unbonded risers and pipelines," University of Stavanger, (2012).

7. A. T. Do, G. Bernard, and D. Hanonge, "Carbon Fiber Armors Applied to Presalt Flexible Pipe Developments,” Offshore Technol. Conf., no. May, pp. 6-9, (2013).

8. P. Obrien, E. Meldrum, C. Overton, J. Picksley, K. Anderson, and I. MacLeod, "Outcomes from the SureFlex Joint Industry Project - An International Initiative on Flexible Pipe Integrity Assurance.” Offshore Technology Conference, (2011).

9. J. Muren, "Flexible Pipes Failure modes, inspection, testing and monitoring," PSA Norw., p. 30, (2007).

10. 4 Subsea, "Un-bonded Flexible Risers - Recent Field Experience and Actions for Increased Robustness," for PSA - Norway, Stavanger,( 2013).

11. S. Frost, Y. Savidis, T. F. Illson, R. Ashworth, S. Heath, J. Cambers, and J. C. Boot, "COREL (Corrosion Resistant Liners) Joint Industry Project (JIP)." NACE International, 2000.

12. M. S. Mehdi and A. K. Al-dossary, "Thermoplastic Lined Pipework for Corrosive Applications," Corros. 2013, no. 2197, pp. 1-7, (2013).

13. W. Soboyejo, Mechanical Properties of Engineered Materials. CRC Press, 2002.

14. A. G. Gibson, "The cost effective use of fibre University of Newcastle Upon Tyne," 2003.

15. B. P. Singh, D. Singh, R. B. Mathur, and T. L. Dhami, "The advantages of epoxy resin versus polyester in marine composite structures," Nanoscale Res. Lett., 2008.

16. A. K. Kaw, Mechanics of Composite Materials. Taylor \& Francis, 1997.

17. M. R. Garcez and S. Filho, "A comparative study of reinforced concrete beams strengthened with glass , carbon and Aramid fibers," no. April, p. 2005, 2005.

18. T. A. Netto, U. S. Ferraz, and S. F. Estefen, "The effect of corrosion defects on the burst pressure of pipelines," J. Constr. Steel Res., 61, 8, pp. 1185-1204, Aug. (2005).

19. B. Bedairi, D. Cronin, A. Hosseini, and A. Plumtree, "Failure prediction for Crack-inCorrosion defects in natural gas transmission pipelines," Int. J. Press. Vessel. Pip., 9697, pp. 90-99, Aug. 2012.

20. D. S. Cronin, “Assessment of corrosion defects in pipelines," UWSpace, 2000.

21. X. Li, Y. Bai, C. Su, and M. Li, "Effect of interaction between corrosion defects on failure pressure of thin wall steel pipeline," Int. J. Press. Vessel. Pip., 138, pp. 8-18, Feb. (2016). 